\title{
Study on the Main Components and Antioxidation in vitro of Insect Tea and its Raw Material Kuding Tea
}

\author{
Chong Li, Xin Zhao* and Bihui Liu
}

\begin{abstract}
In this study, the main components and contents of insect tea and its raw material Kuding tea produced in Guangxi, China were determined by high-performance liquid chromatography (HPLC). The DPPH and ABTS free radical scavenging experiments were used to investigate the scavenging ability of insect tea and its raw material Kuding tea. The results showed that there were neochlorogenic acid, cryptochlorogenic acid, rutin, isochlorogenic acid $\mathrm{A}$ and quercetin in insect tea and Kuding tea. The difference is that the insect tea also contains hesperidin, but the raw material Kuding tea also contains isochlorogenic acid B and kaempferoside, and the content is different to some extent. Insect tea and its raw material Kuding tea have the ability of scavenging free radicals. Compared with insect tea, the raw material Kuding tea has stronger ability of scavenging free radicals.
\end{abstract}

Keywords - Insect tea, Kuding tea, antioxidant, high-performance liquid chromatography.

\section{INTRODUCTION}

Kuding tea is mainly distributed in Guangdong, Fujian and other places in China. It is a traditional pure natural drink [1]. There are more than 200 components in Kuding tea, such as saponins, amino acids, vitamin $\mathrm{C}$, polyphenols, flavonoids, caffeine, protein, etc. It has the functions of lowering blood lipid, increasing coronary blood flow, increasing myocardial blood supply and anti-atherosclerosis [2].

Insect tea is not a kind of tea, but the excrement of the larvae of rice borer. Kuding tea is slightly steamed to remove astringency, and then discharged by the larvae after oral administration. The excrement is dried to make insect tea [3]. Insect tea has the health care effects of clearing away heat, strengthening stomach, detoxifying and helping digestion. It

Chongqing University of Education (Bihui Liu)

Chongqing Collaborative Innovation Center for Functional Food China

Chongqing University of Education (Xin Zhao)

Chongqing Collaborative Innovation Center for Functional Food China

Chongqing University of Education (Chong Li)

Chongqing Collaborative Innovation Center for Functional Food China also has special effects on some diseases, and has become a famous export tea with Chinese characteristics [4].

In this study, insect tea and its raw material Kuding tea were used as the research object. The compounds and contents in insect tea and its raw material Kuding tea were analyzed by HPLC. The free radical scavenging ability of insect tea and its raw material Kuding tea was determined by DPPH and ABTS free radical scavenging experiments.

\section{II.MATERIALS AND METHODS}

\section{A. Materials and reagents}

Both insect tea and Kuding tea were purchased in Guilin, Guangxi, China. The 2, 2'-azino-bis (3-ethylbenzthiazoline-6sulphonic acid) diammonium salt (ABTS) was purchased from Hefei BASF Biotechnology Co., Ltd., and DMSO was purchased from Guangzhou Saiguo Biotechnology Co., Ltd. Isochlorogenic acid $\mathrm{A}$, quercetin, rutin, kaempferin, isochlorogenic acid B, neochlorogenic acid, cryptochlorogenic acid, hesperidin, purchased from Guangzhou analysis and measurement center.

\section{B. HPLC analysis}

The insect tea or its raw material Kuding tea was dissolved in DMSO to obtain a solution with a concentration of $10 \mathrm{mg} / \mathrm{mL}$ and diluted with $50 \%$ methanol to produce a final concentration of $2.5 \mathrm{mg} / \mathrm{mL}$. The sample was passed through a $0.22-\mu \mathrm{m}$ organic filter before testing. Ten microliters of the diluted sample solution were analyzed using an UltiMate3000 HPLC System (Thermo Fisher Scientific, Inc., Waltham, MA, USA) and separated using an Accucore C18 column (2.6 um, 4.6×150 $\mathrm{mm}$; Thermo, America). Mobile phase A was water containing $0.5 \%$ acetic acid, and mobile phase $\mathrm{B}$ was acetonitrile. The flow rate was $0.5 \mathrm{~mL} / \mathrm{min}$ with a column temperature of $25^{\circ} \mathrm{C}$, and the detection wavelength was $280 \mathrm{~nm}$. The gradient elution conditions were as follows: 0-15 min with $15-20 \%$ B (linear gradient), $15-35$ min with 20-40\% B (linear gradient), 35-45 min with 40-70\% B (linear gradient), 45-50 min with 70-100\% B (linear gradient), and 50-55 min with 100\% B (isocratic).

\section{Free radical scavenging activity}

The DPPH radical scavenging experiment was used to determine the oxidation effect of insect tea and raw tea. The $50 \%$ methanol solution was added to the insect tea powder (or 
Kuding tea powder) (v:v, $20: 1)$, water bath at $60^{\circ} \mathrm{C}$ for $30 \mathrm{~min}$, ultrasound for $15 \mathrm{~min}$, and the extract was then evaporated to remove the water and methanol using a rotary evaporator (N-1100; Eyela; Tokyo, Japan) and then freeze-dried and stored at $4{ }^{\circ} \mathrm{C}$ until required. A total of $0.2 \mathrm{~mL}$ of different concentrations of insect tea and raw tea samples $(0.0,0.2,0.4$, $0.6,0.8,1.0 \mathrm{mg} / \mathrm{mL}$ ) was added to $4.0 \mathrm{~mL}$ of DPPH methanol solution $(0.15 \mathrm{mM})$. Afterwards, the solution was mixed gently and left in the dark at room temperature for 30 minutes. The absorbance of the solution was determined at $517 \mathrm{~nm}$ using a UV-visible spectrophotometer (BioMate 3S; Thermo Fisher Scientific, Inc., Waltham, MA, USA). The sample absorbance and background absorbance were then deducted. The measurements were performed three times and averaged [5].

The ABTS reagent $(6.83 \mathrm{mM}$ ) was mixed (volume, 1:1) with $\mathrm{K}_{2} \mathrm{~S}_{2} \mathrm{O}_{8}(2.47 \mathrm{mM})$, oxidized for 12 hours at room temperature in the dark, and diluted with absolute methanol to an absorbance of $0.7 \pm 0.02(734 \mathrm{~nm})$. A total of $0.2 \mathrm{~mL}$ of different concentrations of the samples $(0.0,0.2,0.4,0.6,0.8,1.0$ $\mathrm{mg} / \mathrm{mL}$ ) was added to $3.0 \mathrm{~mL}$ of the above ABTS working solution, mixed, and placed in a dark environment for 10 minutes at room temperature. Absorption was measured at 734 $\mathrm{nm}$. The sample absorbance and background absorbance were deducted. These experimental procedures were repeated three times [6].

\section{RESULTS}

The results of HPLC analysis of insect tea and Kuding tea are as follows.

TABLE I

CONTENT OF MAIN COMPONENTS IN INSECT TEA

\begin{tabular}{|c|c|}
\hline Component & Content $(\mathbf{m g} / \mathbf{g})$ \\
\hline Neochlorogenic acid & 0.90 \\
\hline Cryptochlorogenic acid & 2.04 \\
\hline Rutin & 6.43 \\
\hline Isochlorogenic acid A & 1.64 \\
\hline Hesperidin & 1.63 \\
\hline Quercetin & 1.59 \\
\hline
\end{tabular}

TABLE II

CONTENT OF MAIN COMPONENTS IN RAW LEAVES OF INSECT TEA

\begin{tabular}{|c|c|}
\hline Component & Content $(\mathbf{m g} / \mathbf{g})$ \\
\hline Neochlorogenic acid & 1.86 \\
\hline Cryptochlorogenic acid & 0.59 \\
\hline Rutin & 7.58 \\
\hline Kaempferitrin & 10.23 \\
\hline Quercetin & 0.66 \\
\hline Isochlorogenic acid A & 2.52 \\
\hline & \\
\hline
\end{tabular}

DPPH is a stable free radical with nitrogen as the center. When it encounters a strong free radical scavenger, the single electron of DPPH is captured, which makes the color of the solution lighter, and the absorption value at the maximum light absorption wavelength decreases [7]. The in vitro antioxidant effect of insect tea and raw tea Kuding tea can be preliminarily determined by calculating the measured photometric value. The results showed that the scavenging capacity of insect tea to DPPH radical was $12.04,15.38,23.17,29.32$ and $32.94 \%$ respectively at the concentration of $0.2,0.4,0.6,0.8$ and $1 \mathrm{mg} /$ $\mathrm{mL}$, and that of Kuding tea was 40.00, 78.11, 87.99, 89.85, $90.68 \%$, respectively at the concentration of $0.2,0.4,0.6,0.8$ and $1 \mathrm{mg} / \mathrm{mL}$ in $50 \%$ methanol. Insect tea and its raw material Kuding tea have a certain DPPH free radical scavenging ability at the concentration of $0-1 \mathrm{mg} / \mathrm{ml}$. compared with insect tea, its raw material Kuding tea has a stronger DPPH free radical scavenging ability. When the concentration of Kuding tea is $1 \mathrm{mg} / \mathrm{ml}$, the scavenging ability of DPPH reaches $90.68 \%$. The results are shown in the figure1-2.

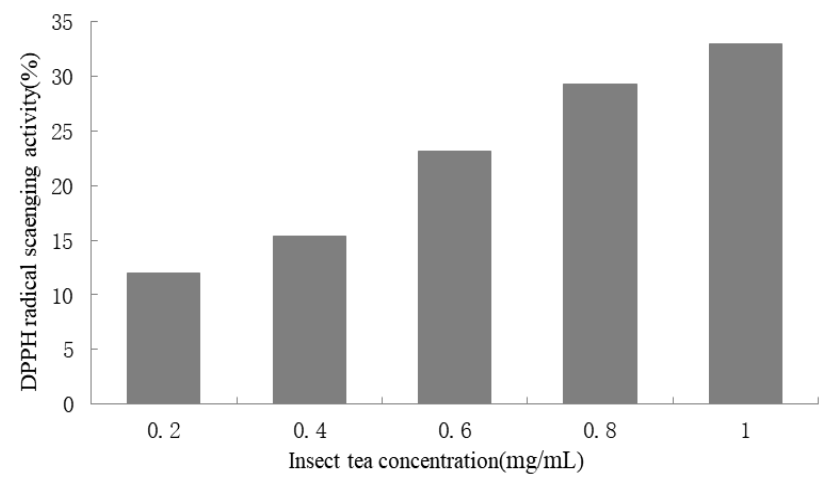

Fig. 1 Antioxidative effect of insect tea on DPPH in vitro

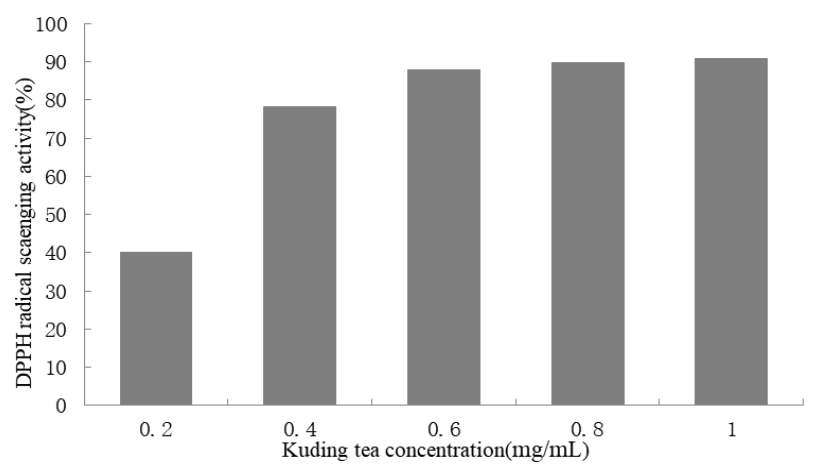

Fig. 2 Antioxidative effect of Kuding tea on DPPH in vitro

ABTS can be oxidized by active oxygen to form the blue-green cation $\mathrm{ABTS}^{+}$. After adding an antioxidant-active substance, the antioxidant reacts with $\mathrm{ABTS}^{+}$to discolor the system [8]. The scavenging ability of insect tea to ABTS ${ }^{+}$ radicals was $5.58,9.64,11.97,13.30$ and $14.93 \%$ at the concentration $0.2,0.4,0.6,0.8$ and $1 \mathrm{mg} / \mathrm{mL}$ in $50 \%$ methanol, and that of Kuding tea was 25.87, 48.92, 73.78, 96.22 and $98.44 \%$ at the concentration of $0.2,0.4,0.6,0.8$ and $1 \mathrm{mg} / \mathrm{mL}$ in $50 \%$ methanol. Through the preliminary analysis of the data, it can be seen that insect tea and its raw tea Kuding tea have the anti-oxidation effect at the concentration of $0-1 \mathrm{mg} / \mathrm{mL}$. In contrast, the antioxidant capacity of Kuding tea is stronger than that of insect tea. When Kuding tea was $0.8 \mathrm{mg} / \mathrm{mL}$, the scavenging rate of ABTS was $96.2 \%$. The results are as follows 
(Fig. 3-4).

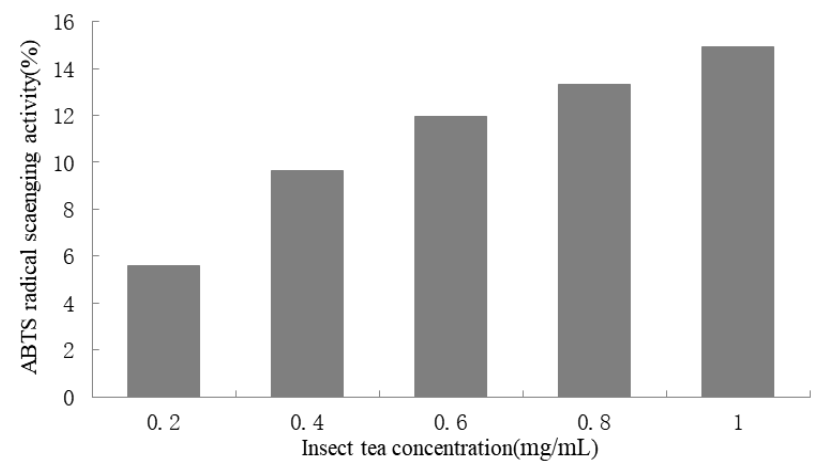

Fig. 3 Antioxidative effect of insect tea on ABTS in vitro

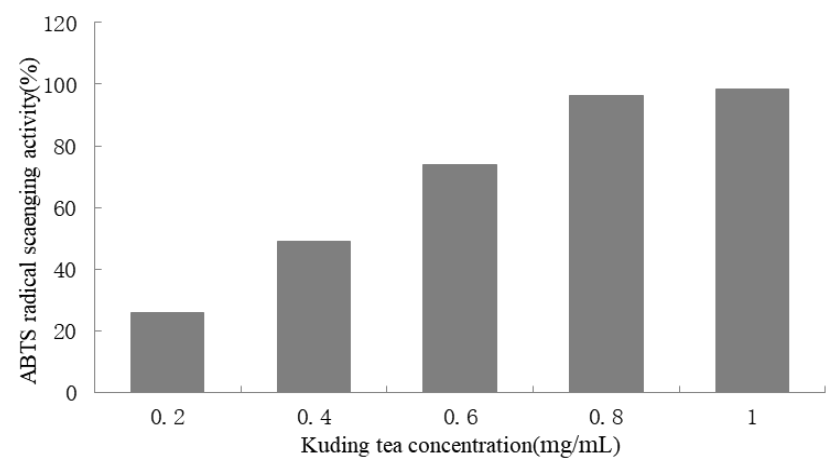

Fig. 4 Antioxidative effect of Kuding tea on ABTS in vitro

\section{CONCLUSIONS}

In conclusions, there are mainly neochlorogenic acid, cryptochlorogenic acid, rutin, isochlorogenic acid $\mathrm{A}$, hesperidin and quercetin in insect tea, and neochlorogenic acid, cryptochlorogenic acid, rutin, kaempferin, quercetin, isochlorogenic acid A and isochlorogenic acid B in Kuding tea by HPLC. The content of rutin is more in insect tea, and the content of kaempferoside is more in Kuding tea. In addition, Free radical scavenging experiment (DPPH and ABTS) were used to study the antioxidation of insect tea and its raw material Kuding tea in vitro, which showed that both insect tea and raw material tea had the antioxidative effect, and the antioxidative ability of raw material Kuding tea is stronger than that of insect tea. This study, however, was only a preliminary examination of the compounds and antioxidant of insect tea; the specific biological activities, anti-cancer effects, and mechanisms of the various biologically active compounds in the extracts will be the topics of future studies.

\section{REFERENCES}

[1] Pu L. H., Liu X. D., Guo Y., et al, "Preliminary study on antioxidant capacity of Ilex Kudingcha," Journal of agricultural products processing, 2014, pp. 10-12.

[2] Wei X. J., Yin H., Meng F., et al, "Research progress of active ingredients and pharmacological activities of Kudingcha," China Medical Journal, 2017, pp. 62-65.
[3] Li, J. R., Zhou, L. T, "Current situation of Chinese insect tea and way of further research and development.Academic Periodical of Farm Products Processing," 2005, pp. 4-7.

[4] Liu,F. R., Wang, Q., Zhang, J., Zhao, X, "In vitro anticancer effect of Ilex kudingcha Tseng in MCF-7 human breast adenocarcinoma cells.Journal of Hebei University (Natural Science Edition),” 2013, pp. 185-192.

[5] Zhao, X., Wang, Q., Li, G., Chen, F., Qian, Y., Wang, R, "In vitro antioxidant, anti-mutagenic, anti-cancer and anti-angiogenic effects of Chinese Bowl tea," Journal of Functional Foods. 2014, pp.590-598. https://doi.org/10.1016/j.jff.2013.12.026

[6] Zhang, H., Yang, Y., Zhou, Z, "Phenolic and flavonoid contents of mandarin (Citrus reticulata Blanco) fruit tissues and their antioxidant capacity as evaluated by DPPH and ABTS methods," Journal of Integrative Agriculture. 2018, pp.256-263. https://doi.org/10.1016/S2095-3119(17)61664-2

[7] Sharma, O.P., Bhat, T.K, "DPPH antioxidant assay revisited. Food Chem," 2009, vol.113, pp.1202-1205. https://doi.org/10.1016/j.foodchem.2008.08.008

[8] Irina, I.K., Harm, A.G.N., Beek, T.A.V, "Application of ABTS Radical Cation for Selective On-Line Detection of Radical Scavengers in HPLC Eluates," Anal. Chem. 2001, vol.73, pp.3373-3381.

https://doi.org/10.1021/ac0013610 